\title{
RSK4 inhibits breast cancer cell proliferation and invasion in vitro, and is correlated with estrogen receptor upregulation in breast cancer
}

\author{
HONG HUO $^{1 *}$, XINQING YE ${ }^{2 *}$, HONGHE YANG $^{1}$, QIUYUN LI $^{1}$ and YI JIANG ${ }^{1}$ \\ Departments of ${ }^{1}$ Breast Surgery and ${ }^{2}$ Pathology, Guangxi Medical University Cancer Hospital, \\ Nanning, Guangxi Zhuang Autonomous Region 530021, P.R. China
}

Received April 12, 2019; Accepted August 20, 2019

DOI: $10.3892 /$ or.2019.7328

\begin{abstract}
Estrogen (E2) receptor (ER) upregulation has been associated with tumor progression and is the most commonly used clinical biomarker in breast cancer. X-linked ribosomal S6 kinase 4 (RSK4) is downregulated in breast cancer and may act as a tumor suppressor gene. In order to understand the association between the ER and RSK4, the present study studied the effects of RSK4 on ER-positive $\left(\mathrm{ER}^{+}\right)$breast cancer cell function, and the effects of E2 on RSK4 function and RSK4 methylation. Furthermore, the disease-free survival of patients with breast cancer with RSK4 hypermethylation/hypomethylation was investigated to establish the link between RSK4 methylation on patient prognosis. The expression levels of RSK4 were increased and RSK4 promoter methylation was decreased in $\mathrm{ER}^{+}$breast cancer tissues and cell lines compared with ER-negative breast cancer tissues and cell lines, respectively. ER expression was negatively correlated with RSK4 expression and positively associated with RSK4 methylation. In vitro overexpression of RSK4 decreased the proliferation, clone formation, migration and angiogenesis and increased apoptosis of breast cancer cells. Patients with RSK4 hypomethylation exhibited a longer disease-free survival compared with patients with RSK4 hypermethylation. E2 stimulation of breast cancer cells increased ER expression and RSK4 methylation, which was associated with decreased RSK4 expression. Furthermore, ER upregulation was proposed to be related to the decreased expression of RSK4 in $\mathrm{ER}^{+}$breast cancer. E2
\end{abstract}

Correspondence to: Dr Qiuyun Li or Dr Yi Jiang, Department of Breast Surgery, Guangxi Medical University Cancer Hospital, 71 Hedi Road, Nanning, Guangxi Zhuang Autonomous Region 530021, P.R. China

E-mail: qyli1020@sina.com

E-mail: cat7921@sina.com

*Contributed equally

Key words: breast cancer, estrogen receptor, X-linked ribosomal S6 kinase 4 methylation signaling may therefore act upstream of RSK4 to promote cancer progression. The results obtained in the current study suggested that RSK4 inhibited breast cancer cell invasiveness and that RSK4 promoter hypomethylation may serve as a novel prognostic marker for patients with breast cancer.

\section{Introduction}

Breast cancer is one of the most common types of cancer in females, with 2.1 million newly diagnosed cases in 2018 alone, accounting for $25 \%$ of all female cancer diagnoses (1). Approximately $15 \%$ of all female cancer-associated mortalities in the United States of America were attributed to breast cancer (2). Current treatment therapies include surgical treatment, chemotherapy, radiotherapy and endocrine therapy $(3,4)$. However, treatment may be ineffective, particularly due to the development of chemotherapy and endocrine therapy resistance. There is therefore a requirement for the identification of novel therapeutic strategies for the treatment of breast cancer.

$\mathrm{X}$-linked ribosomal S6 kinase 4 (RSK4) is a serine-threonine protein kinase (5) that participates in the regulation of cellular senescence (6) and in tumor protein P53-dependent cell growth arrest signaling, acting as an inhibitor during embryogenesis (7). The distribution RSK4 in normal and tumor tissues has not been systematically investigated. Aberrant RSK4 expression has been reported in several types of cancer, including breast cancer (8), colorectal cancer (9), acute myeloid leukemia (10), non-small cell lung carcinoma (11), endometrial cancer (12) and ovarian cancer $(13,14)$. Several studies have demonstrated that RSK4 is downregulated in breast cancer and may therefore act as a tumor suppressor gene $(8,15-17)$. Additionally, downregulation of RSK4 in breast cancer is associated with hypermethylation of the RSK4 promoter $(8,15)$.

The sex hormone estrogen (E2) is involved in the growth, development and physiology of the mammary glands. E2 binds to the E2 receptor (ER) $\alpha$ or $\beta$ and regulates cellular proliferation and differentiation. ER $\alpha$ upregulation occurs in $\sim 70 \%$ of breast cancer cases $(18,19)$ and is associated with tumor progression $(20,21)$. ER upregulation is the most commonly used clinical biomarker for breast cancer and ER-positive $\left(\mathrm{ER}^{+}\right)$breast cancer is amenable to endocrine therapy (22). E2 stimulation promotes the expression of RSK4 in normal 
mammary epithelial cells and the expression of RSK4 in breast cancer cells is closely associated with RSK4 methylation (15). ER signaling may therefore affect the expression of RSK4 or the methylation of the RSK4 promoter.

The present study explored the association between ER status, RSK4 expression and promoter methylation in breast cancer tissues. Additionally, the role of RSK4 and the effect of ER signaling on RSK4 promoter methylation in $\mathrm{ER}^{+}$breast cancer cells were investigated.

\section{Materials and methods}

Tumor tissue specimens. A total of 60 female patients who underwent breast surgery at the Guangxi Medical University Cancer Hospital between January 2013 to December 2014 were included in the current study. The clinical characteristics of the patients are presented in Table I. The patients had a mean age of 45.3 years (range, 25-71 years). The inclusion criteria were as follows: i) Pathological diagnosis of luminal A or luminal type B invasive breast cancer; and ii) no family history of breast cancer. Patients who had received tumor-associated treatment (including radiotherapy and chemotherapy) prior to admission were excluded from the current study.

Surgical resection specimens were obtained in the Department of Breast Surgery at the Guangxi Medical University Cancer Hospital. Breast cancer tissue and non-cancerous glandular tissue samples (at a distance of $\geq 2 \mathrm{~cm}$ from the tumor edge) were obtained from all patients. All samples were immediately placed in liquid nitrogen, stored at $80^{\circ} \mathrm{C}$ and subsequently embedded in paraffin. The present study was approved by the Research Ethics Committee of the Guangxi Medical University Cancer Hospital and patients provided written informed consent.

Cell culture. The ER ${ }^{+}$human breast cancer cell line MCF-7 and the ER- human breast cancer cell lines MDA-MB-231 and MDA-MB-453 were purchased from the Chinese Academy of Sciences. The breast cancer cell lines were cultured in Dulbecco's Modified Eagles medium (DMEM; HyClone; GE Life Sciences) containing $10 \%$ fetal bovine serum (FBS; Sigma-Aldrich; Merck KGaA). 293T and human umbilical vein endothelial cells (HUVECs) were purchased from the Chinese Academy of Sciences. All cells were maintained at $37^{\circ} \mathrm{C}$ and $5 \% \mathrm{CO}_{2}$.

Lentiviral packaging and cell transfection. The RSK4 lentiviral expression vector carrying the RSK4 coding sequence (pLenti-RSK4; 650 ng/ $\mu \mathrm{l}$; Thermo Fisher Scientific, Inc.) was co-transfected into 293T cells together with the packaging plasmids (Invitrogen; Thermo Fisher Scientific, Inc.). Medium containing lentiviral particles was subsequently harvested $48 \mathrm{~h}$ following transfection. Lentivirus stock was stored at $-80^{\circ} \mathrm{C}$ and used to infect MCF-7 cells in subsequent experiments.

MCF-7 cells were seeded in 6-well plates at a density of $3 \times 10^{5}$ cells/well. Upon reaching $70 \%$ confluence, the cells were transfected with the lenti-RSK4-eGFP virus (RSK4-OE) or a lenti-eGFP virus as a negative control (NC) at a multiplicity of infection of 30. Nontransfected MCF-7 cells served as additional controls. Transfections were performed in triplicate. Cells were observed 24, 48 and $72 \mathrm{~h}$ following transfection using bright field/fluorescence microscopes (magnification, $\mathrm{x} 100$; three fields), and the transfection efficiency was further assessed by western blotting.

Immunohistochemistry. Paraffin blocks containing fixed tissues were sliced into $4-\mu \mathrm{m}$ sections, placed on a glass slide, dewaxed with xylene and dehydrated using an alcohol gradient $(100,95,70,50 \%)$. Endogenous peroxidase activity was blocked by incubating the sections in $3 \%$ hydrogen peroxide at $37^{\circ} \mathrm{C}$ for $10 \mathrm{~min}$. Samples were microwaved at high power for $4 \mathrm{~min}$ and low power for $20 \mathrm{~min}$ and allowed to reach room temperature to allow antigen recovery. Sections were immersed in normal goat serum (Abcam) for $10 \mathrm{~min}$ and subsequently incubated overnight at $4^{\circ} \mathrm{C}$ with primary antibodies against ER (1:500; Abcam, Ab75635) and RSK4 (1:1,000; Abcam, Ab76117). Following primary antibody incubation, samples were incubated with rabbit secondary antibody (1:200; Jackson ImmunoResearch Laboratories Inc., cat. no. 117360), stained with DAB (Beijing Solarbio Science \& Technology Co., Ltd.) for $2 \mathrm{~min}$ and counterstained with hematoxylin for $5 \mathrm{~min}$ at room temperature. Samples were visualized using a DM750 microscope (Leica, Germany).

ER and RSK4 staining was independently assessed by two senior pathologists. Three randomly selected fields were scored under 100x magnification using a light microscope. A total of 200 cells were scored per field, with $\geq 600$ cells scored per section. ER and RSK4 staining was scored as follows: i) $<10 \%$ Positively stained cells, 0 points; ii) $10-30 \%$ positively stained cells, 1 point; iii) $31-60 \%$ positively stained cells, 2 points; and iv) $>61 \%$ positively stained cells, 3 points. ER and RSK4 staining was additionally scored for color intensity as follows: i) Colorless, 0 points; ii) light yellow, 1 point; iii) brown, 2 points; and iv) tan, 3 points. The overall level of ER and RSK4 expression was determined by multiplying the two scores as follows: i) 0-1 Points, negative; ii) 1.1-2.0 points, weakly positive; iii) $2.1-3.0$, moderately positive; and iv) 3.1-5.0 staining, strongly positive.

RNA extraction and reverse-transcription quantitative polymerase chain reaction $(R T-q P C R)$. Total RNA was extracted from patient tissue samples and transduced cells using TRIzol $^{\circledR}$ reagent (Thermo Fisher Scientific, Inc.) according to the manufacturer's protocol. The RNA was reverse-transcribed into cDNA using the RevertAid First Strand cDNA Synthesis kit (Thermo Fisher Scientific, Inc.) in accordance with the manufacturer's instructions. qPCR was subsequently performed using SYBR ${ }^{\circledR}$ Green mix (Thermo Fisher Scientific, Inc.) according to the manufacturer's protocol at Mx3000P Real-time fluorescence quantification PCR instrument (Agilent Technologies, Inc.). The thermocycling conditions were as follows: $95^{\circ} \mathrm{C}$ for $2 \mathrm{~min}$, followed by 40 cycles of $95^{\circ} \mathrm{C}$ for $15 \mathrm{sec}, 60^{\circ} \mathrm{C}$ for $20 \mathrm{sec}$ and $72^{\circ} \mathrm{C}$ for $20 \mathrm{sec}$ and a final extension step $60.5^{\circ} \mathrm{C}$ for $30 \mathrm{sec}$. mRNA levels were quantified using the $2^{-\Delta \Delta \mathrm{Cq}}$ method (23) and normalized to $\beta$-actin. Primer sequences were as follows: RSK4 forward, 5'-AGATTCTCCCGGTTTGCC-3' and reverse, 5'-AAGGGTCTCGCTTACTTTTGT-3'; $\beta$-actin forward, 5'-GGCACTCTTCCAGCCTTCC-3' and reverse, 5'-GAGCCG CCGATCCACAC-3'.

Western blotting. Cells were lysed with cell lysis buffer (Beyotime Institute of Biotechnology) and the protein 
Table I. Characteristics of 60 patients with breast cancer, stratified by molecular subtype.

\begin{tabular}{|c|c|c|c|c|c|}
\hline Characteristic & Total & Luminal A & Luminal B1 & Luminal B2 & P-value \\
\hline $\mathrm{n}(\%)$ & $60(100)$ & $21(35)$ & $19(32)$ & $20(33)$ & \\
\hline Age (years), $\mathrm{n}$ & & & & & $0.858^{\mathrm{a}}$ \\
\hline$<45$ & 24 & 9 & 8 & 10 & \\
\hline$\geq 45$ & 36 & 12 & 11 & 10 & \\
\hline Median (range) & & $45(30-65)$ & $45(28-71)$ & $46(25-69)$ & \\
\hline Menopausal status, $\mathrm{n}$ & & & & & $0.859^{\mathrm{a}}$ \\
\hline Premenopausal & 28 & 11 & 10 & 12 & \\
\hline Postmenopausal & 32 & 10 & 9 & 8 & \\
\hline \multicolumn{6}{|l|}{ Pathology type, $\mathrm{n}$} \\
\hline Invasive ductal carcinoma & 60 & 21 & 19 & 20 & \\
\hline T stage, $\mathrm{n}$ & & & & & $0.744^{\mathrm{b}}$ \\
\hline $\mathrm{T} 1$ & 8 & 2 & 4 & 2 & \\
\hline $\mathrm{T} 2$ & 23 & 8 & 8 & 7 & \\
\hline $\mathrm{T} 3$ & 29 & 11 & 7 & 11 & \\
\hline N stage, $\mathrm{n}$ & & & & & $0.922^{\mathrm{b}}$ \\
\hline No & 6 & 2 & 3 & 1 & \\
\hline N1 & 28 & 10 & 8 & 10 & \\
\hline $\mathrm{N} 2$ & 26 & 9 & 8 & 9 & \\
\hline TNM stage, $\mathrm{n}$ & & & & & $0.783^{\mathrm{b}}$ \\
\hline IA & 3 & 1 & 2 & 0 & \\
\hline IIA & 9 & 3 & 4 & 2 & \\
\hline IIB & 25 & 8 & 7 & 10 & \\
\hline IIIA & 23 & 9 & 6 & 8 & \\
\hline \multicolumn{6}{|l|}{ Hormone receptor status, $\mathrm{n}$} \\
\hline Positive & 60 & 21 & 19 & 20 & \\
\hline Negative & - & - & - & - & \\
\hline Tumor nuclear grade, $\mathrm{n}$ & & & & & $0.387^{\mathrm{b}}$ \\
\hline I & 18 & 5 & 6 & 7 & \\
\hline II & 20 & 6 & 9 & 5 & \\
\hline III & 22 & 10 & 4 & 8 & \\
\hline
\end{tabular}

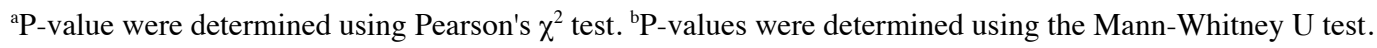

concentration was determined using a Pierce ${ }^{\mathrm{TM}}$ BCA Protein Assay kit (Thermo Fisher Scientific, Inc.). Protein aliquots (30 $\mu \mathrm{g} /$ lane) were separated via SDS-PAGE on a $10 \%$ gel. The separated proteins were subsequently transferred onto a polyvinylidene difluoride membrane and blocked with 5\% skim milk powder in Tris-buffered saline with Tween-20 (TBST) for $1 \mathrm{~h}$ at room temperature. The membranes were incubated with primary antibodies against RSK4 (1:1,000; Abcam), ER (1:400; Abcam) and GAPDH (1:1,000; Sungene), $\beta$-actin $(1: 2,000$; Boster Biological Technology) or tubulin (1:2,000; Sungene) overnight at $4^{\circ} \mathrm{C}$. Following three washes with TBST, the membranes were incubated with rabbit HRP secondary antibodies against RSK4 and ER (1:3,000; Jackson ImmunoResearch Laboratories Inc.), and GAPDH, $\beta$-actin and tubulin) (1:3,000; Jackson ImmunoResearch Laboratories Inc.) for $1 \mathrm{~h}$ at room temperature. The membranes were washed three times with TBST and protein bands were visualized using the Tanon-4200 automatic chemiluminescence image analysis system (Tanon-4200 Fully Automatic Chemiluminescence Image Analyzer, Tianneng).

DNA extraction and bisulfite sequencing. Genomic DNA was extracted from patient tissues and cells and treated with bisulfite using the EZ DNA Methylation-Gold ${ }^{\mathrm{TM}}$ kit (Zymo Research Corp.) according to the manufacturer's protocols. The bisulfite-treated DNA was subsequently amplified by PCR using the following primer pair: RSK4 forward, 5'-TGA GAGGGTTTGTTGAGTATGTGTG-3' and reverse, 5'-CCT CTATACTACCTCTCCAAAAACTAC-3'. The PCR products were cloned into the pMD19-T vector (Takara Biotechnology Co., Ltd.) according to manufacturer's protocols. The ligation product $(10 \mu \mathrm{l})$ was transformed into DH5 $\alpha$ competent cells (Invitrogen; Thermo Fisher Scientific, Inc.) using the conversion method. The cells were subsequently plated onto Luria broth (LB; Thermo Fisher Scientific, Inc.) plates containing $0.1 \mathrm{mg} / \mathrm{ml}$ ampicillin and cultured overnight at $37^{\circ} \mathrm{C}$. Eight 

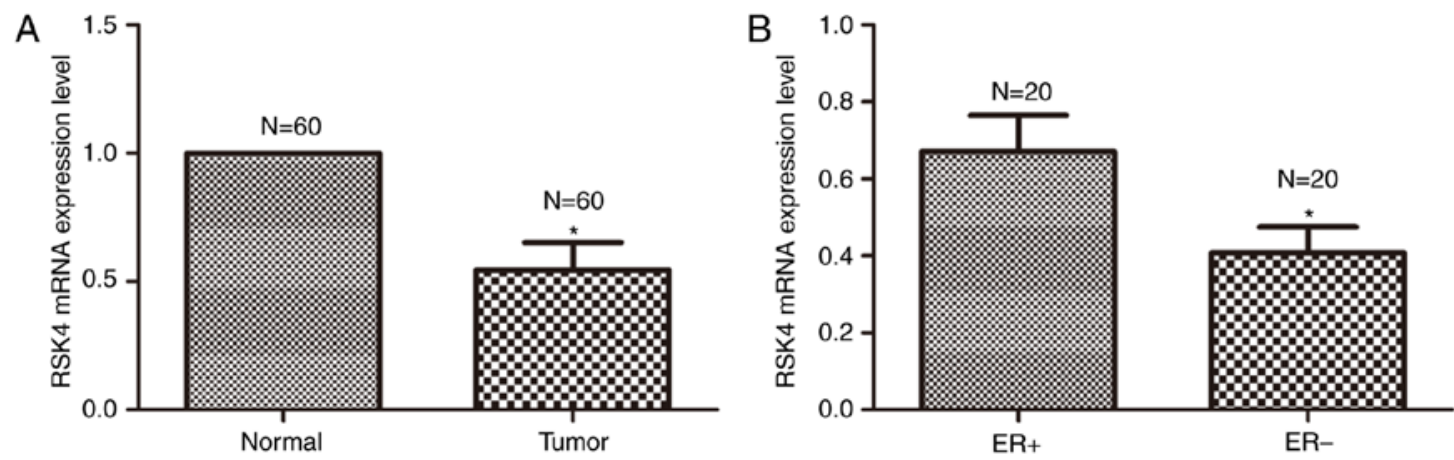

ER
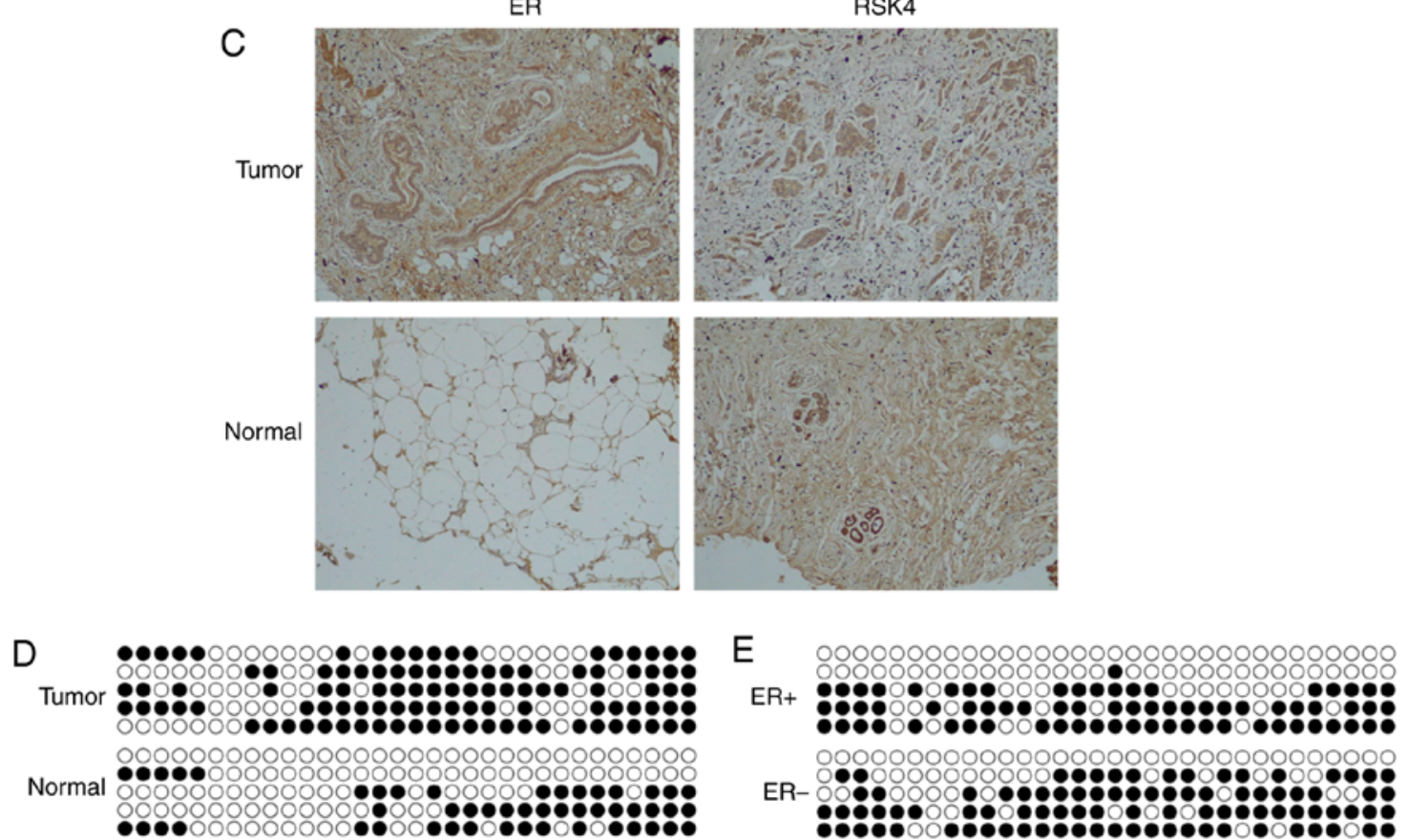

Figure 1. Expression of RSK4 in breast cancer tissue. Levels of RSK4 mRNA, as measured by reverse-transcription quantitative PCR, were compared (A) between breast cancer and paired adjacent normal tissues, as well as (B) between $\mathrm{ER}^{+}$and ER breast cancer tissues. (C) and RSK4 protein expression in breast cancer and paired adjacent normal tissues, as assessed by immunohistochemistry. Magnification, x400. (D) Bisulfite map showing RSK4 promoter methylation in breast cancer and paired adjacent normal tissues. (E) RSK4 promoter methylation levels in $\mathrm{ER}^{+}$and ER tumor tissue. Black circles indicated methylated $\mathrm{CpGs}$ and white circles presented unmethylated $\mathrm{CpGs}$. Five clones were sequenced per locus. ${ }^{*} \mathrm{P}<0.05$ vs. Normal or ER ${ }^{+}$. RSK4, X-linked ribosomal S6 kinase 4; ER, estrogen receptor.

bacterial colonies were selected from each plate and the presence of the insert was confirmed by PCR as aforementioned. Colonies containing the cloned inserts (at least 5 per plate) were inoculated in $3 \mathrm{ml} \mathrm{LB}$ containing $0.1 \mathrm{mg} / \mathrm{ml}$ ampicillin and cultured overnight at $37^{\circ} \mathrm{C}$. Plasmids were extracted using the AxyPerp Plasmid Miniprep kit (Axygen; Corning, Inc.) and analyzed using the Quantification Tool For Methylation Analysis (quma.cdb.riken.jp). Five clones were sequenced per locus.

Cell proliferation assay. The proliferation of transduced cells was determined using the Cell Counting Kit-8 (CCK-8; Dojindo Molecular Technologies, Inc.). Cells were seeded in a 96-well plate at a density of $3 \times 10^{3}$ cells per well and cultured at $37^{\circ} \mathrm{C}$. A total of $10 \mu \mathrm{l} \mathrm{CCK}-8$ solution was added following 1,2 , 3,4 and 5 days of incubation, and cells were incubated at $37^{\circ} \mathrm{C}$ for a further $2 \mathrm{~h}$. Cell proliferation was subsequently measure at a wavelength of $450 \mathrm{~nm}$ a microplate reader (Thermo Fisher Scientific, Inc.). Samples were analyzed in triplicate.
Clone formation assay. A total of $2 \mathrm{ml}$ transfected cell suspension $\left(1 \times 10^{3}\right.$ cells $\left./ \mathrm{ml}\right)$ were added to each well of a 6 -well plate and cultured until 30-50 cell clusters had formed, 5-7 days later. The spent cell culture medium was discarded and the cells were fixed in methanol $\left(0.1 \%, 37^{\circ} \mathrm{C}, 15 \mathrm{~min}\right)$ and stained with crystal violet $\left(0.1 \%, 37^{\circ} \mathrm{C}, 20 \mathrm{~min}\right)$. Clones were counted using an inverted fluorescence microscope (Olympus Corporation; magnification, $\mathrm{x} 100)$. Clone formation was calculated as the number of clones formed/number of cells seeded $\times 100 \%$.

Cell migration assay. A total of $100 \mu 1$ transfected cell suspension was pipetted into the upper chamber of 24-well Transwell inserts at a density of $4 \times 10^{4}$ cells per well. The lower chamber was filled with DMEM supplemented with 10\% FBS. Cells were incubated at $37^{\circ} \mathrm{C}$ and $5 \% \mathrm{CO}_{2}$ for $24 \mathrm{~h}$, after which the cells in the upper chamber that had not migrated through the polycarbonate membrane were wiped off. Cells in the lower chamber were fixed with $4 \%$ paraformaldehyde (Beijing Solarbio Science \& Technology Co., Ltd.) for $30 \mathrm{~min}$ at $37^{\circ} \mathrm{C}$ 

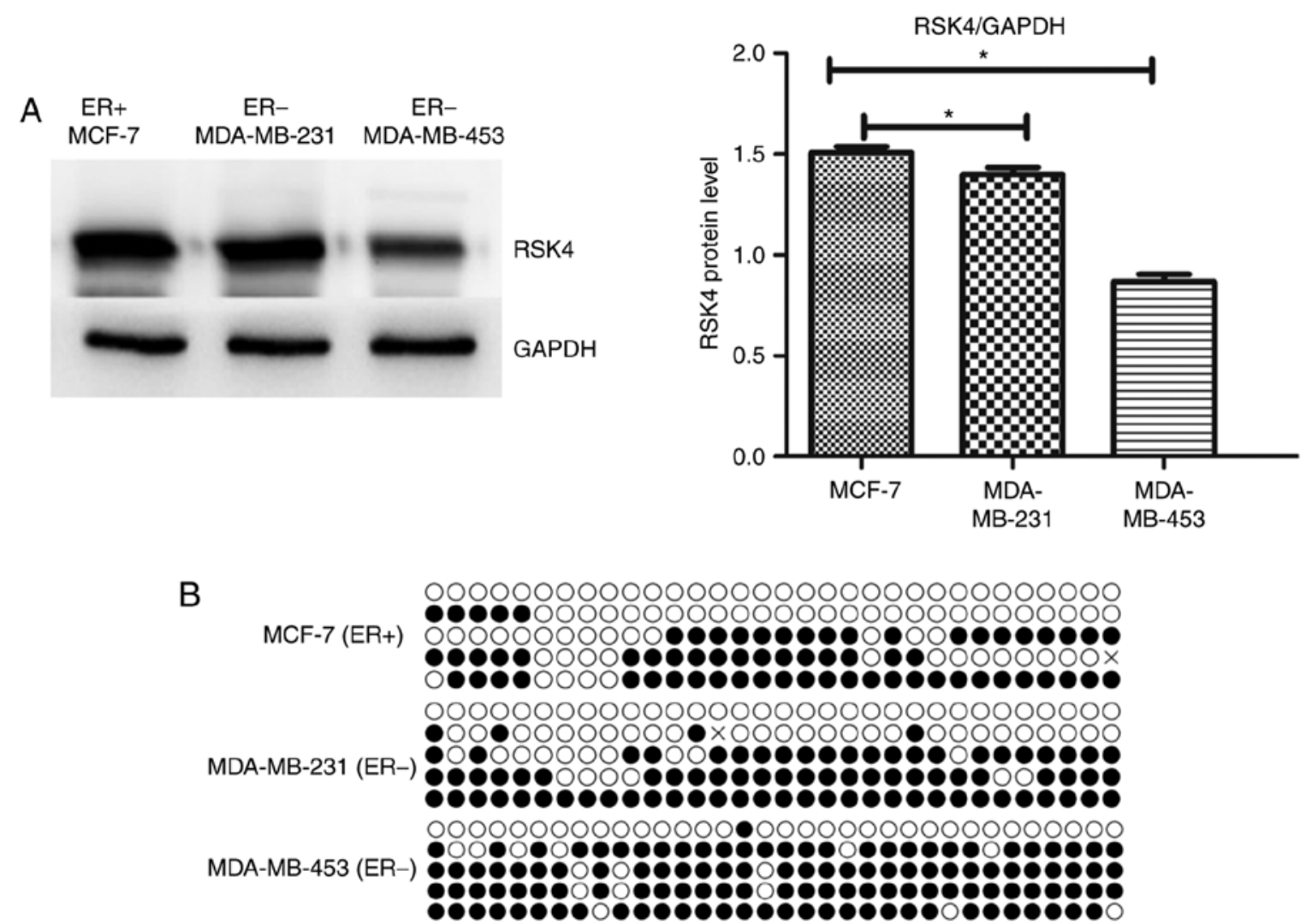

Figure 2. Expression of RSK4 in breast cancer cell lines. (A) Western blot analysis of RSK4 protein levels in MCF-7, MDA-MB-231 and MDA-MB-453 cells. (B) Bisulfite map showing RSK4 promoter methylation in MCF-7, MDA-MB-231 and MDA-MB-453 cells. Black circles indicated methylated CpGs and white circles presented unmethylated CpGs. Five clones per locus were sequenced. "P<0.05. RSK4, X-linked ribosomal S6 kinase 4; X, no available data.

and stained with $0.1 \%$ crystal violet (Beijing Solarbio Science $\&$ Technology Co., Ltd.) for $20 \mathrm{~min}$ at $37^{\circ} \mathrm{C}$. The cells were subsequently washed three times with PBS. Stained cells were counted in five randomly selected fields using an inverted fluorescence microscope (Olympus Corporation; magnification, x100). Each well was counted in triplicate.

Flow cytometry. After $48 \mathrm{~h}$ following transduction, cells were washed with PBS, trypsinized and suspended in $500 \mu \mathrm{l}$ binding buffer which was included in the kit. Cells were subsequently incubated with $5 \mu \mathrm{l}$ Annexin V-allophycocyanin (APC) and $5 \mu$ propidium iodide (PI; Annexin V-APC-PI Apoptosis Analysis kit; Sungene) in the dark at room temperature for 10-15 min. Annexin V fluorescence was measured using a FACSAria Cell Sorter c6 flow cytometer (Accuri C6; BD Biosciences). The experiment was performed in triplicate.

Angiogenesis assay. Matrigel (BD Biosciences) was pipetted into a 96 -well plate $(50 \mu \mathrm{l} /$ well $)$, incubated for $30 \mathrm{~min}$ at $4^{\circ} \mathrm{C}$ and allowed to set for $30 \mathrm{~min}$ at $37^{\circ} \mathrm{C}$. A total of $5 \times 10^{4} \mathrm{HUVECs}$ suspended in $50 \mu \mathrm{l}$ serum-free conditioned medium taken from MCF-7 cells cultured for $24 \mathrm{~h}$ were seeded on Matrigel-coated wells. Endothelial tube formation was assessed following $5 \mathrm{~h}$ of culture and the mean number of tubes was counted in three randomly selected fields per well using an inverted fluorescence microscope (Olympus Corporation; magnification, x100).

E2 induction of MCF-7 cells. MCF-7 cells were plated into a 6 -well plate at a density of $3 \times 10^{5}$ cells/well and incubate at $37^{\circ} \mathrm{C}$ and $5 \% \mathrm{CO}_{2}$. E2 (Sigma-Aldrich; Merck KGaA) was diluted in dimethyl sulfoxide (Beijing Solarbio Science \& Technology Co., Ltd.) to prepare a stock solution of $10 \mathrm{mM}$ and added to MCF-7 cells at final concentrations of 1,5 or $10 \mathrm{nM}$. Cells were subsequently incubated with E2 for $48 \mathrm{~h}$ at $37^{\circ} \mathrm{C}$. Untreated MCF-7 cells served as controls. Cells were imaged prior and following treatment using an inverted fluorescence microscope (Olympus Corporation; magnification, x100; three random fields were selected).

Disease-free survival and overall survival. The 60 patients with breast cancer enrolled in the current study were followed-up by telephone or by electronic medical records until November 30 , 2018. The median follow-up time was 52 months (range, 10-66 months). Local recurrence was defined as recurrence in the ipsilateral chest wall or regional lymph nodes detected by imaging or histology. Distant metastasis was defined as distant metastatic lesions detected by imaging. Disease-free survival was defined as time from the date of surgery to recurrence or metastasis. Overall survival was defined as time from the date of surgery to death. Patients with RSK4 methylation levels above or equal to the mean methylation value of 60 patients were defined as hypermethylated, while those with RSK4 methylation below the mean were defined as hypomethylated. Patient characteristics are presented in Table I.

Statistical analysis. Data were presented as mean \pm standard deviation. Data were analyzed using SPSS software (version 19; IBM Corp.). A Student's t-test was used for the 
A
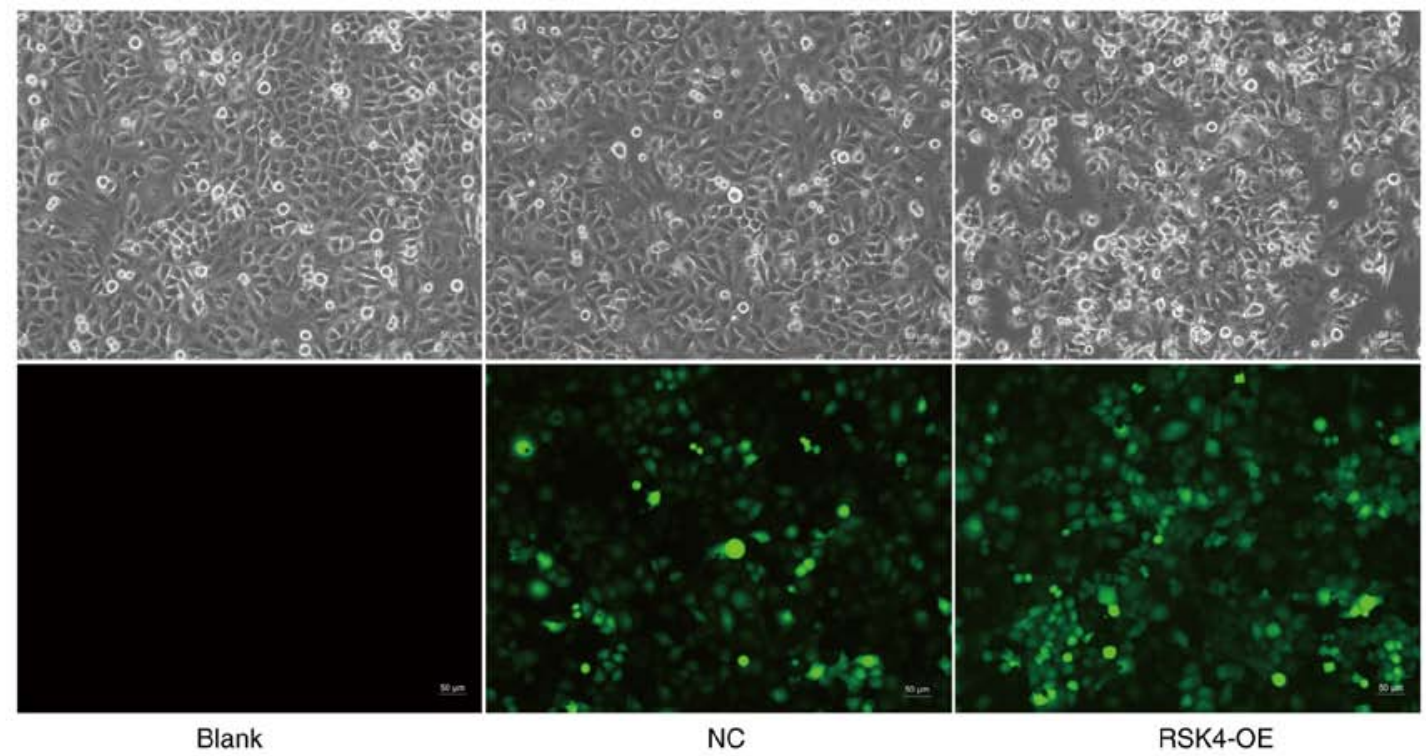

Blank

NC

RSK4-OE

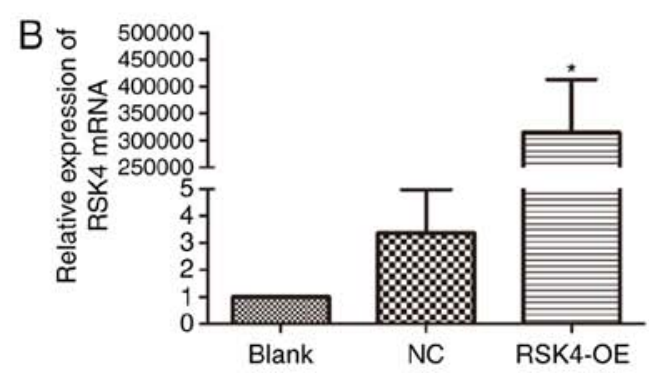

C
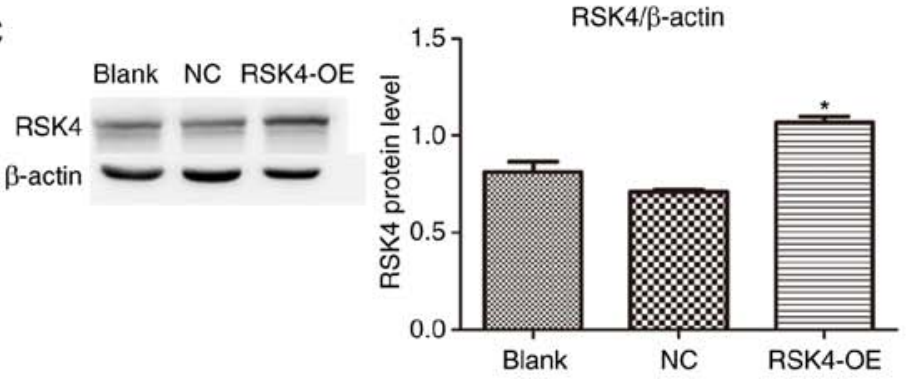

Figure 3. RSK4 OE in MCF-7 cells $72 \mathrm{~h}$ following transfection. (A) Bright field (upper row) and fluorescence (lower row) micrographs of MCF-7 cells transfected with RSK4-OE or NC. Magnification, x400. (B) RSK4 mRNA expression levels in MCF-7 cells transfected with RSK4-OE or NC, and in nontransfected controls (blank). Expression values were normalized to the blank group. (C) RSK4 protein levels in MCF-7 cells transfected with lenti-RSK4-EGFP or NC, and in nontransfected controls (blank). $\beta$-actin was used as a loading control. " $\mathrm{P}<0.05$ vs. NC and blank. RSK4, X-linked ribosomal S6 kinase 4; NC, negative control; OE, overexpression.

comparison of two groups while one-way ANOVA was used for the comparison of three or more groups followed by a Least Significant Difference post-hoc test. Pearson's correlation analysis was used to assess the correlation of ER status with RSK4 expression. Patient survival was assessed using the Kaplan-Meier method, and survival curves were compared using the log-rank test. $\mathrm{R} \times \mathrm{C}$ bidirectional disordered count data were analyzed via a Pearson's $\chi^{2}$ test. Grade data were analyzed via a Mann-Whitney $U$ test. $\mathrm{P}<0.05$ was considered to indicate a statistically significant difference. Three independent experiments were performed.

\section{Results}

$E R^{+}$status is associated with higher RSK4 expression and lower promoter methylation in breast cancer tissue compared with $E R^{-}$status. The current study examined whether there was an association between RSK4 expression and breast cancer by comparing breast cancer and adjacent normal tissues. RSK4 mRNA expression was significantly decreased in breast cancer tissues compared with adjacent normal tissues $(\mathrm{P}=0.003$; Fig. 1A). Similarly, immunohistochemical analysis revealed that RSK4 protein expression was markedly decreased in breast cancer tissues compared with adjacent normal tissues (Fig. 1C). ER protein expression was notably increased in breast cancer tissues compared with adjacent normal tissues (Fig. 1C). Bisulfite sequencing revealed that RSK4 promoter methylation was increased in breast cancer tissues compared with adjacent normal tissues (66.2 vs. $31.2 \%$; Fig. 1D).

The association between RSK4 expression and ER status in breast cancer was investigated by analyzing $\mathrm{ER}^{+}$and $\mathrm{ER}^{-}$ tumor tissues. RSK4 mRNA expression was significantly decreased in $\mathrm{ER}^{-}$breast cancer tissues compared with $\mathrm{ER}^{+}$ breast cancer tissues $(\mathrm{P}=0.037$; Fig. 1B).Bisulfite sequencing demonstrated that RSK4 promoter methylation was decreased in $\mathrm{ER}^{+}$breast cancer tissues compared with ER' breast cancer tissues (45 vs. $56.9 \%$; Fig. 1E).

$E R^{+}$status is associated with increased RSK4 protein levels and decreased promoter methylation in breast cancer cell lines compared with ER- status. The RSK4 protein levels in breast cancer cell lines were assessed using western blotting. Similarly to the mRNA data obtained from patient tissue samples, RSK4 protein expression was significantly increased in the $\mathrm{ER}^{+}$breast cancer cell line MCF-7 compared with the $\mathrm{ER}^{-}$breast cancer cell lines MDA-MB-231 $(\mathrm{P}=0.037)$ and MDA-MB-453 ( $\mathrm{P}<0.001$; Fig. 2A). The aforementioned results suggested that RSK4 expression decreased with increasing tumor malignancy as MDA-MB-231 and MDA-MB-453 cells have a higher degree of malignancy than MCF-7 cells (24). 


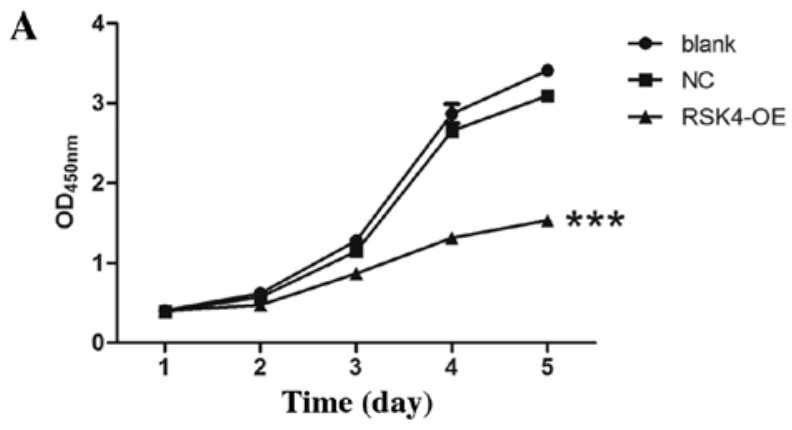

B

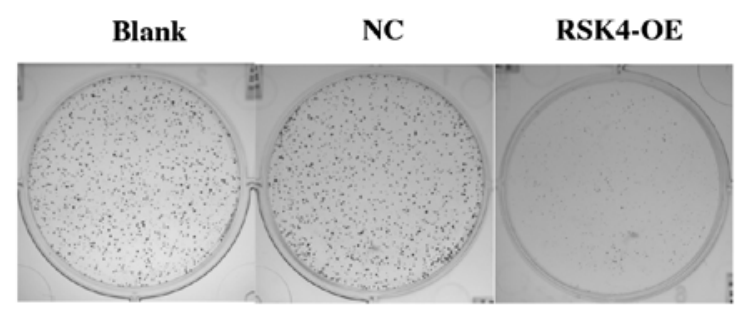

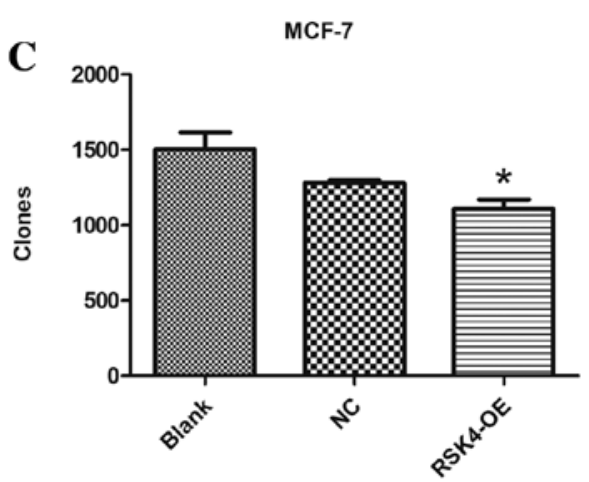

Figure 4. Effects of RSK4 OE on the proliferation of MCF-7 breast cancer cells. (A) Growth curves of MCF-7 cells transfected with RSK4-OE or NC, and nontransfected controls (blank), as measured by a Cell Counting Kit-8 assay. (B) Plates of clone formation in MCF-7 cells transfected with RSK4-OE or NC, and blank cells. (C) Quantitation of the experiments. Results are presented as the mean \pm standard deviation. ${ }^{*} \mathrm{P}<0.05$ and ${ }^{* * *} \mathrm{P}<0.001$ vs. NC and blank. RSK4, X-linked ribosomal S6 kinase 4; NC, negative control; OE, overexpression.

A

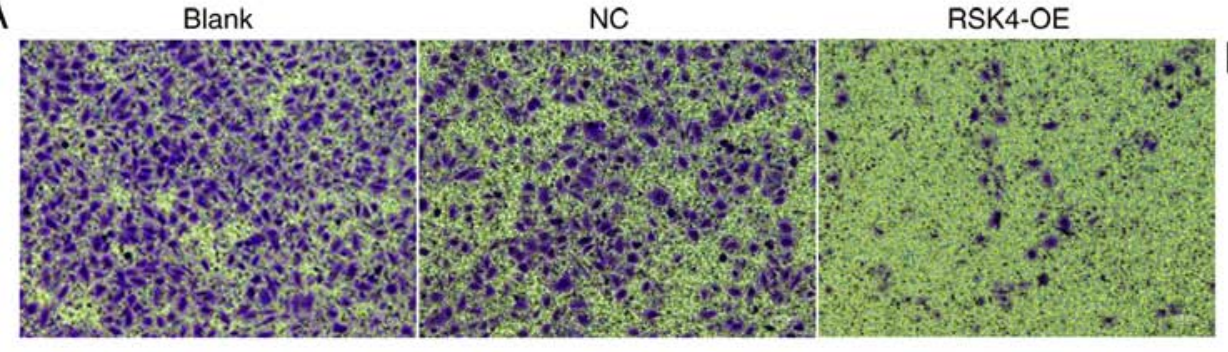

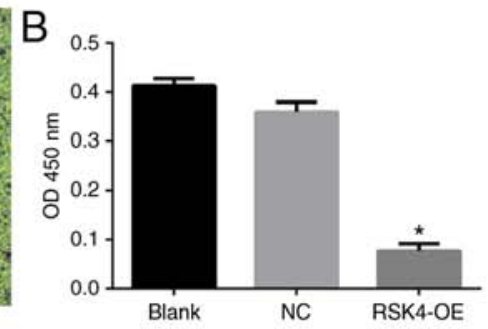

Figure 5. Effects of RSK4 OE on the migration of MCF-7 breast cancer cells. (A) images of migratory MCF-7 cells transfected with RSK4-OE or NC, and nontransfected controls (blank). Magnification, $\mathrm{x} 100$. (B) Quantitation of the experiments. Results are presented as the mean \pm standard deviation. " $\mathrm{P}<0.05$ vs. NC and blank. RSK4, X-linked ribosomal S6 kinase 4; NC, negative control; OE, overexpression.
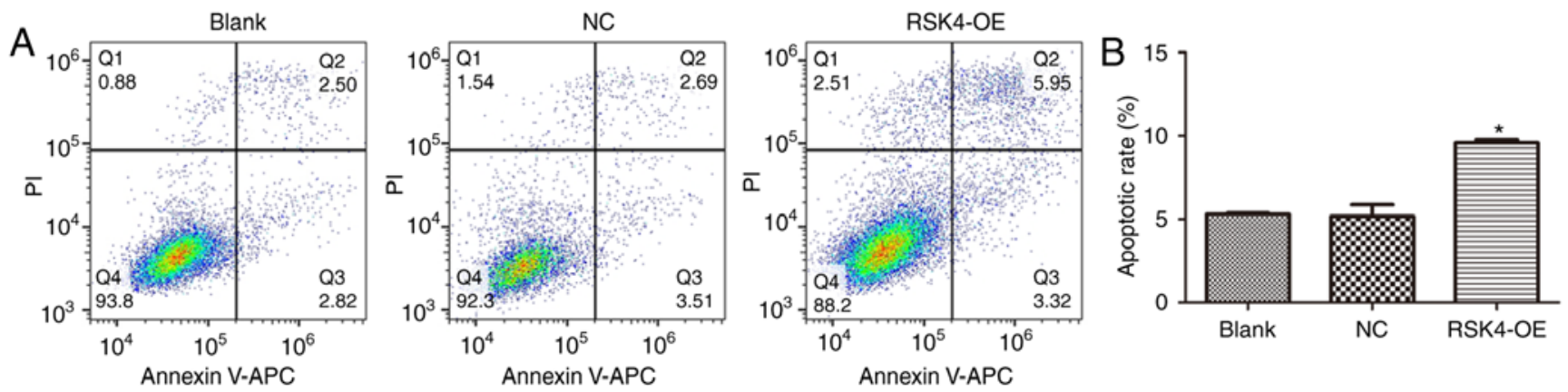

Figure 6. Effects of RSK4 OE on apoptosis level in MCF-7 breast cancer cells. (A) Annexin V-APC fluorescence in MCF-7 cells transfected with RSK4-OE or NC, and nontransfected controls (blank). (B) Quantification of the experiments. Results are presented as the mean \pm SD. "P<0.05 vs. NC and blank. APC, allophycocyanin; RSK4, X-linked ribosomal S6 kinase 4; NC, negative control; OE, overexpression; PI, propidium iodide.

Furthermore, the $\mathrm{ER}^{+}$breast cancer cell line MCF-7 exhibited decreased RSK4 promoter methylation (compared with the
ER' breast cancer cell lines MDA-MB-231 and MDA-MB-453 (42.8 vs. $52.8 \%$ and $71.8 \%$, respectively; Fig. $2 \mathrm{~B})$. 

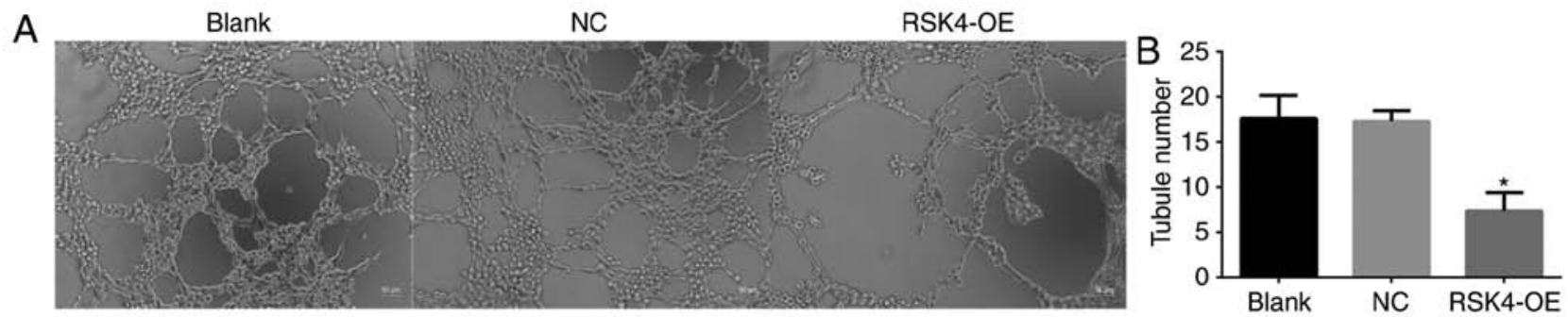

Figure 7. Effects of conditioned medium from MCF-7 overexpressing RSK4 on HUVEC tube formation. HUVECs were exposed to conditioned medium from MCF-7 cells transfected with RSK4-OE or NC, and nontransfected controls (blank). (A) Representative photomicrographs. Magnification, x400. (B) Quantification of tubule number from the experiments (A) Results are presented as the mean \pm standard deviation. "P<0.05 vs. NC and blank. RSK4, X-linked ribosomal S6 kinase 4; HUVECs, human umbilical vein endothelial cells; NC, negative control; OE, overexpression.
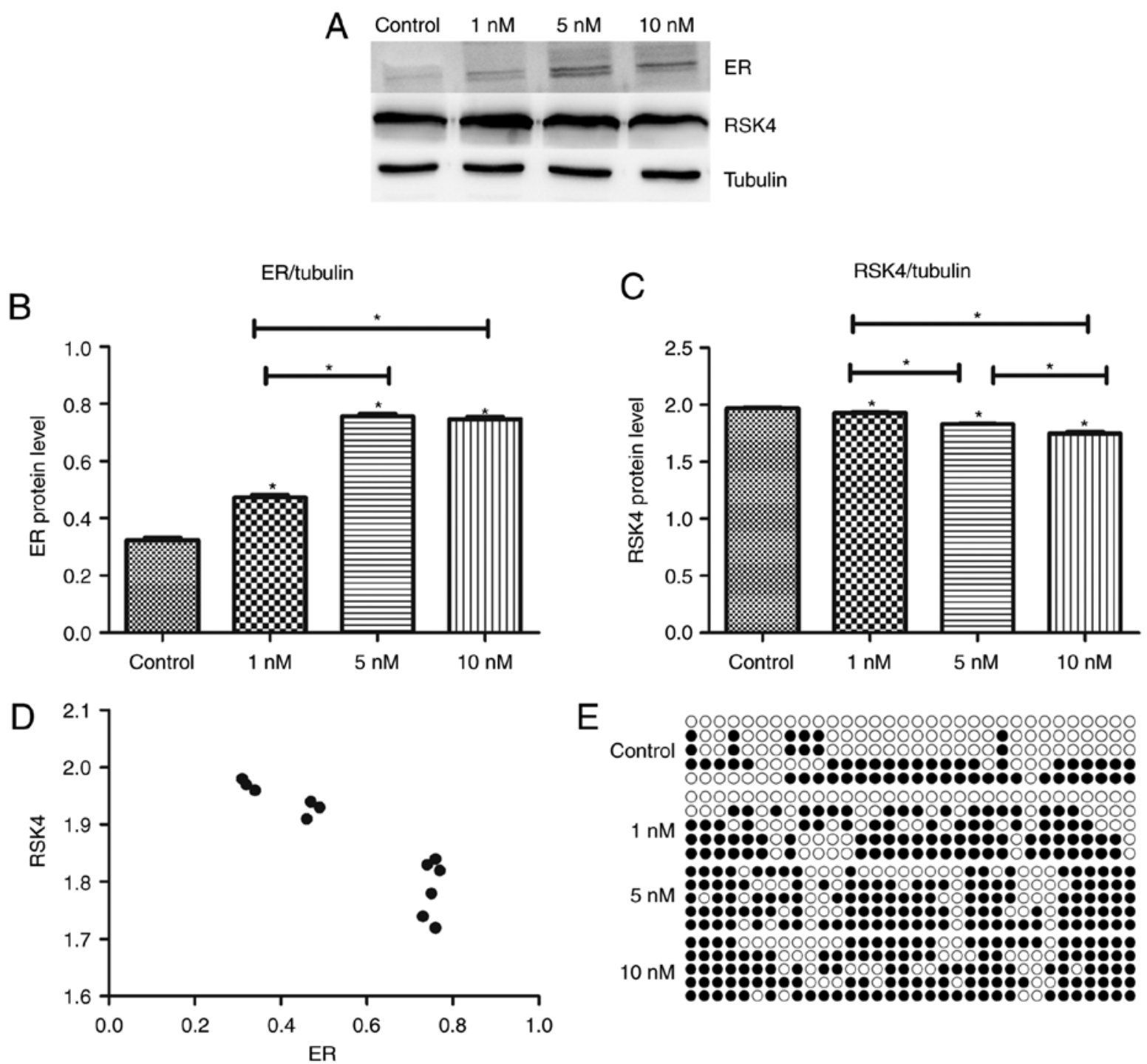

Figure 8. Effects of estrogen stimulation on ER and RSK4 expression and RSK4 promoter methylation in MCF-7 cells. (A-C) ER and RSK4 protein levels in MCF-7 cells treated with the indicated estrogen concentrations for $48 \mathrm{~h}$. (D) Correlation analysis between ER and RSK4. (E) Bisulfite map showing RSK4 promoter methylation in MCF-7 cells treated with the indicated estrogen concentrations for $48 \mathrm{~h}$. Black circles indicate methylated CpGs and white circles unmethylated CpGs. Five clones per locus were sequenced. "P<0.05. ER, estrogen receptor; RSK4, X-linked ribosomal S6 kinase 4.

RSK4 overexpression inhibits the proliferation and clone formation in $E R^{+}$breast cancer cells. To investigate the effects of RSK4 overexpression on breast cancer cells, MCF-7 breast cancer cells were transfected with RSK4-OE or Lenti-EGFP (NC) vectors. MCF-7 cells were selected since they are $\mathrm{ER}^{+}$ breast cancer cells. Cells transfected with RSK4-OE exhibited a notable increase in EGFP fluorescence over $72 \mathrm{~h}$; the transfection efficiency was over 80\% (Fig. 3A). Quantitation of RSK4 mRNA and protein by RT-qPCR and western blotting revealed that RSK4-OE cells exhibited a significant increase 


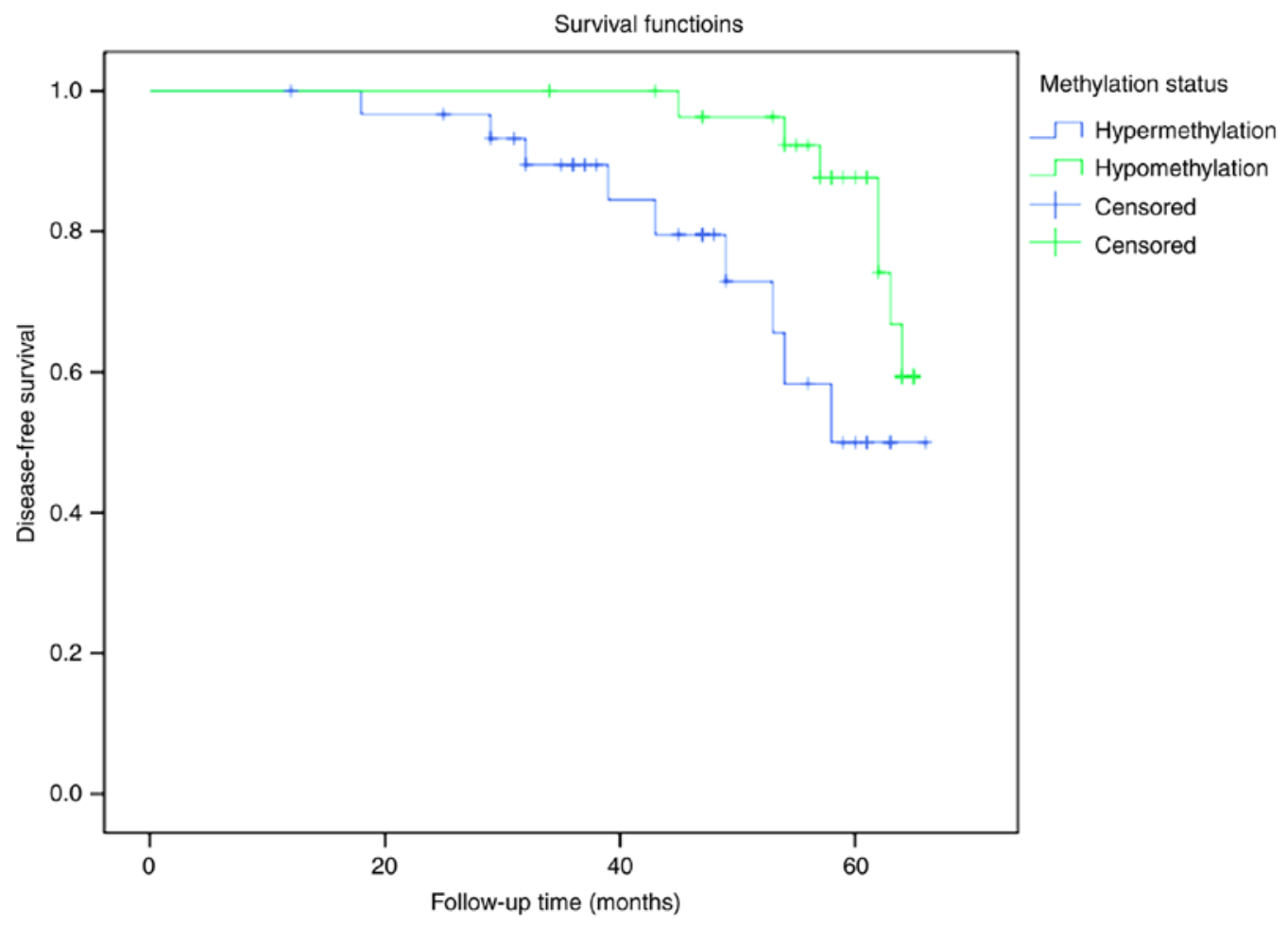

Figure 9. Association between RSK4 promoter methylation level and disease-free survival in 60 patients with breast cancer. Patients were stratified based on the mean methylation level. RSK4, X-linked ribosomal S6 kinase 4.

in RSK4 expression compared with NC cells (RSK4 mRNA, $\mathrm{P}=0.008$; RSK4 protein, $\mathrm{P}=0.002$ ) and nontransfected cells (RSK4 mRNA, P=0.008; RSK4 protein, $\mathrm{P}<0.001$; Fig. 3B and $\mathrm{C}$ ). No significant differences were observed between NC and nontransfected cells.

The proliferation of transfected cells was assessed using a CCK-8 assay. RSK4-OE cells exhibited significant decreases in the proliferation compared with $\mathrm{NC}(\mathrm{P}<0.001)$ and nontransfected groups $(\mathrm{P}<0.001$; Fig. 4A). Furthermore, RSK4-OE cells formed significantly fewer clones than NC cells $(\mathrm{P}=0.001)$ and nontransfected cells $(\mathrm{P}<0.001$; Fig. $4 \mathrm{~B}$ and $\mathrm{C}$ ). There was no difference between NC cells and nontransfected cells.

$R S K 4$ overexpression reduces the migration of $E R^{+}$breast cancer cells. The effects of RSK4 overexpression on the migration of transfected MCF-7 cells was assessed using a Transwell assay. RSK4-OE cells exhibited significantly reduced migration compared with $\mathrm{NC}$ cells $(\mathrm{P}<0.001)$ and nontransfected cells $(\mathrm{P}<0.001$; Fig. 5A and $\mathrm{B})$. There was no significant difference in migration between NC and nontransfected cells.

RSK4 overexpression promotes the apoptosis in ER $R^{+}$breast cancer cells. Flow cytometry analysis of cells stained with Annexin V-APC and PI revealed that RSK4-OE cells exhibited a significant increase in the number of apoptotic cells compared with the $\mathrm{NC}(\mathrm{P}<0.001)$ and nontransfected cells $(\mathrm{P}<0.001$; Fig. 6). There was no significant difference in apoptosis between NC cells and nontransfected cells $(\mathrm{P}=0.822)$.

RSK4 overexpression reduces HUVEC tubule formation in vitro. The effects of RSK4 on the ability of HUVECs to form tubes in vitro was assessed. HUVECs were incubated with conditioned medium from nontransfected MCF-7 cells, and those transfected with RSK4-OE or NC cultured for $24 \mathrm{~h}$. Cultured medium from RSK4-OE cells induced significantly fewer tubules compared with $\mathrm{NC}(\mathrm{P}=0.001)$ and nontransfected controls ( $\mathrm{P}=0.001 ;$ Fig. 7$)$. There was no significant difference in tubule formation between conditioned medium from $\mathrm{NC}$ and nontransfected cells.

E2 stimulation of MCF-7 cells increases the expression of ER and RSK4 promoter methylation, but decreases the expression of RSK4. To investigate the effects of E2 signaling on ER and RSK4 expression, MCF-7 cells were treated with E2 for 48 h. ER protein levels were significantly increased in treated cells compared with untreated controls $(\mathrm{P}<0.001)$. Furthermore, ER protein levels were increased in the 5 and $10 \mathrm{nM}$ groups compared with the $1 \mathrm{nM}$-treated group $(\mathrm{P}<0.001)$. There was no significant difference between the 5 and $10 \mathrm{nM}$ groups $(\mathrm{P}=0.446$; Fig. 8A and B). RSK4 protein levels were decreased in the treated cells compared with the untreated controls $(\mathrm{P}<0.05)$. RSK4 protein levels were significantly decreased in the 5 and $10 \mathrm{nM}$ groups compared with the $1 \mathrm{nM}$ group $(\mathrm{P}<0.001)$, and it was lower in the $10 \mathrm{nM}$ group compared with the $5 \mathrm{nM}$-treated group $(\mathrm{P}=0.001$; Fig. 8A and C). ER and RSK4 expression exhibited a negative correlation $(\mathrm{r}=-0.914 ; \mathrm{P}<0.001$; Fig. 8D). Bisulfite sequencing demonstrated that RSK4 promoter methylation was markedly increased in the $10 \mathrm{nM}$-treated group (75.3\%) compared with the $5 \mathrm{nM}(71.2 \%)$ and $1 \mathrm{nM}$-treated groups, (53.8\%) and the control group (36.9\%; Fig. 8E).

RSK4 hypomethylation correlates with longer disease-free survival in patients. The correlation between RSK4 promoter 
methylation and survival was investigated in the 60 patients with breast cancer enrolled in the current study. Patients with RSK4 methylation levels above or equal to the mean methylation value $(n=31)$ were defined as hypermethylated, while those with RSK4 methylation below the mean $(n=29)$ were defined as hypomethylated. The disease-free survival rate was significantly increased in the hypomethylated group compared with the hypermethylated group $(\mathrm{P}=0.026$; Fig. 9). No patient succumbed due to breast cancer during the follow-up period, so the overall survival could not be compared.

\section{Discussion}

The current study revealed that breast cancer tissues expressed significantly decreased levels of RSK4 and increased RSK4 promoter methylation compared with adjacent normal tissues. Furthermore, RSK4 expression was negatively correlated with ER expression in breast cancer cell lines. In addition, $\mathrm{ER}^{+}$status was associated with increased RSK4 expression and decreased promoter methylation compared with $\mathrm{ER}^{-}$status. RSK4 overexpression inhibited $\mathrm{ER}^{+}$breast cancer cell proliferation, migration and clone formation, and promoted apoptosis. Additionally, conditioned medium from an $\mathrm{ER}^{+}$cell line overexpressing RSK4 inhibited HUVEC tubule formation in vitro. The aforementioned results suggested that RSK4 acts as a tumor suppressor, and its downregulation through the hypermethylation of the RSK4 promoter may be associated with breast cancer. Consistent with this hypothesis, the disease-free survival in the current study was significantly longer among patients with RSK4 promoter hypomethylation than among those with hypermethylation.

Previous studies have revealed that the E2-ER signaling pathway regulates mammary gland growth, development and apoptosis through genomic and non-genomic effects, which alter the expression of genes in normal breast epithelial cells $(25,26)$. Dysregulation of the E2-ER signaling pathway alters the expression of genes, including cell surface heparan sulfate proteoglycans, and function of proteins such as the receptors for insulin-like growth factor and epidermal growth factor (27-31), which in turn dysregulates cell proliferation and mammary gland apoptosis (32-35). Additionally, alterations of the E2-ER signaling pathway may promote the conversion of E2-dependent tumors to non-dependent tumors, which are much more resistant to therapy (36-38). However, few studies have investigated the regulatory kinases and upstream/downstream molecules of the estrogen-ER signaling pathway. The results of the present study suggested a mechanistic link between ER signaling and RSK4 in breast cancer.

The present study revealed that RSK4 expression was reduced in breast cancer tissues compared with adjacent normal tissues, and that RSK4 expression decreased with increasing tumor malignancy. A previous study using a smaller number of breast cancer tissues reported a negative correlation between RSK4 mRNA expression and breast cancer tumor size, and clinical stage (8).

The results obtained in the present study revealed that RSK4 expression may correlate with ER upregulation in breast cancer tissues and cell lines, suggesting a mechanistic link between ER signaling and RSK4. The results revealed that the expression of ER was enhanced with increasing E2 concentration. Additionally, RSK4 protein levels decreased and the methylation of the RSK4 promoter increased with increasing E2 concentration. Furthermore, the expression of the was negatively correlated with the expression of RSK4, suggesting that the E2/ER signaling pathway may regulate the methylation of the RSK4 promoter. Inducing E2/ER signaling in breast cancer cells may therefore increase the methylation of the RSK4 promoter, thereby reducing the expression of RSK4 and affecting the development of breast cancer.

In the present study, patients with breast cancer and RSK4 hypomethylation had longer disease-free survival than patients with RSK4 hypermethylation. RSK4 methylation status may thus serve as an independent prognostic marker in breast cancer. However, an association between methylation status and overall survival was not observed in the current study. In summary, our results suggested that altered estrogen-ER signaling may be associated with decreased RSK4 expression and increased RSK4 methylation in breast cancer, leading to enhanced cell proliferation that may accelerate tumor development.

\section{Acknowledgements}

Not applicable.

\section{Funding}

The present study was supported by a grant from the National Natural Science Foundation of China (grant no. 81560431).

\section{Availability of data and materials}

The datasets used during the present study are available from the corresponding author upon reasonable request.

\section{Authors' contributions}

QL designed, analyzed and revised the experiment. YJ designed and analyzed the experiment. HH conducted experiments, data analysis and article writing. XY conducted data processing and collected specimens. HY carried out specimen collection and follow-up. All authors read and approved the final manuscript and agree to be accountable for all aspects of the research in ensuring that the accuracy or integrity of any part of the work are appropriately investigated and resolved.

\section{Ethics approval and consent to participate}

The present study was approved by the Research Ethics Committee of the Guangxi Medical University Cancer Hospital and patients provided written informed consent.

\section{Patient consent for publication}

Not applicable.

\section{Competing interests}

The authors declare that they have no competing interests. 


\section{References}

1. Bray F, Ferlay J, Soerjomataram I, Siegel RL, Torre LA and Jemal A: Global cancer statistics 2018: GLOBOCAN estimates of incidence and mortality worldwide for 36 cancers in 185 countries. CA Cancer J Clin 68: 394-424, 2018.

2. Siegel RL, Miller KD and Jemal A: Cancer statistics, 2019. CA Cancer J Clin 69: 7-34, 2019.

3. Huang $\mathrm{X}$ and Yin YM: Updates of Chinese society of clinical oncology (CSCO) guideline for breast cancer in 2018. Zhonghua yi xue za zhi (In Chinese) 98: 1213-1217, 2018.

4. Waks AG and Winer EP: Breast cancer treatment: A review. JAMA 321: 288-300, 2019.

5. Houles T and Roux PP: Defining the role of the RSK isoforms in cancer. Seminars Cancer Biol 48: 53-61, 2018.

6. Yin Z, Fan L, Huang G, Wang $\mathrm{H}$ and Wang Z: The possible role of ribosomal protein S6 kinase 4 in the senescence of endothelial progenitor cells in diabetes mellitus. Cardiovasc Diabetol 11: 12 2012.

7. Dummler BA, Hauge C, Silber J, Yntema HG, Kruse LS, Kofoed B, Hemmings BA, Alessi DR and Frödin M: Functional characterization of human RSK4, a new 90-kDa ribosomal S6 kinase, reveals constitutive activation in most cell types. J Biol Chem 280: 13304-13314, 2005.

8. Li Q, Jiang Y, Wei W, Ji Y, Gao H and Liu J: Frequent epigenetic inactivation of RSK4 by promoter methylation in cancerous and non-cancerous tissues of breast cancer. Med Oncol 31: 793, 2014.

9. Cai J, Ma H, Huang F, Zhu D, Zhao L, Yang Y, Bi Jand Zhang T: Low expression of RSK4 predicts poor prognosis in patients with colorectal cancer. Int J Clin Exp Pathol 7: 4959-4970, 2014.

10. Rafiee M, Keramati MR, Ayatollahi H, Sadeghian MH, Barzegar M, Asgharzadeh A and Alinejad M: Down-regulation of ribosomal S6 kinase RPS6KA6 in acute myeloid leukemia patients. Cell J 18: 159-164, 2016.

11. Li A, Liu D, Liu Y, Zhou Y, Du Z and Song J: A pilot study of RSK4 expression in patients with human non-small cell lung carcinoma. Ann Clin Lab Sci 48: 484-489, 2018.

12. Banno K, Yanokura M, Iida M, Masuda K and Aoki D: Carcinogenic mechanisms of endometrial cancer: Involvement of genetics and epigenetics. J Obstet Gynaecol Res 40: 1957-1967, 2014.

13. Niskakoski A, Kaur S, Staff S, Renkonen-Sinisalo L, Lassus H, Jarvinen HJ, Mecklin JP, Bützow R and Peltomäki P: Epigenetic analysis of sporadic and Lynch-associated ovarian cancers reveals histology-specific patterns of DNA methylation. Epigenetics 9: $1577-1587,2014$.

14. Arechavaleta-Velasco F,Zeferino-Toquero M,Estrada-Moscoso I, Imani-Razavi FS, Olivares A, Perez-Juarez CE and Diaz-Cueto L: Ribosomal S6 kinase 4 (RSK4) expression in ovarian tumors and its regulation by antineoplastic drugs in ovarian cancer cell lines. Med Oncol 33: 11, 2016.

15. Jiang Y, Ye X, Ji Y, Zhou X, Yang H, Wei W and Li Q: Aberrant expression of RSK4 in breast cancer and its role in the regulation of tumorigenicity. Int J Mol Med 40: 883-890, 2017.

16. Zhu J, Li QY, Liu JL, Wei W, Yang HW and Tang W: RSK4 knockdown promotes proliferation, migration and metastasis of human breast adenocarcinoma cells. Oncol Rep 34: 3156-3162, 2015.

17. Zhu L, Zhang S, Huan X, Mei Y and Yang H: Down-regulation of TRAF4 targeting RSK4 inhibits proliferation, invasion and metastasis in breast cancer xenografts. Biochem Biophys Res Commun 500: 810-816, 2018.

18. Harvey JM, Clark GM, Osborne CK and Allred DC: Estrogen receptor status by immunohistochemistry is superior to the ligand-binding assay for predicting response to adjuvant endocrine therapy in breast cancer. J Clin Oncol 17: 1474-1481, 1999.

19. Musgrove EA and Sutherland RL: Biological determinants of endocrine resistance in breast cancer. Nat Rev Cancer 9: 631-643, 2009.

20. Leary AF, Drury S, Detre S, Pancholi S, Lykkesfeldt AE, Martin LA, Dowsett M and Johnston SR: Lapatinib restores hormone sensitivity with differential effects on estrogen receptor signaling in cell models of human epidermal growth factor receptor 2-negative breast cancer with acquired endocrine resistance. Clin Cancer Res 16: 1486-1497, 2010.

21. Nguyen PL, Taghian AG, Katz MS, Niemierko A, Abi Raad RF, Boon WL, Bellon JR, Wong JS, Smith BL and Harris JR: Breast cancer subtype approximated by estrogen receptor, progesterone receptor, and HER-2 is associated with local and distant recurrence after breast-conserving therapy. J Clin Oncol 26: 2373-2378, 2008.
22. Srinivasan S, Nwachukwu JC, Bruno NE, Dharmarajan V, Goswami D, Kastrati I, Novick S, Nowak J, Cavett V, Zhou HB, et al: Full antagonism of the estrogen receptor without a prototypical ligand side chain. Nat Chem Biol 13: 111-118, 2017.

23. Livak KJ and Schmittgen TD: Analysis of relative gene expression data using real-time quantitative PCR and the 2(-Delta Delta $\mathrm{C}(\mathrm{T}))$ method. Methods 25: 402-408, 2001.

24. Jiang G, Dong S, Yu M, Han X, Zheng C, Zhu X and Tong X: Influence of gap junction intercellular communication composed of connexin 43 on the antineoplastic effect of adriamycin in breast cancer cells. Oncol Lett 13: 857-866, 2017.

25. Acconcia F, Fiocchetti M and Marino M: Xenoestrogen regulation of ERalpha/ERbeta balance in hormone-associated cancers. Mol Cell Endocrinol 457: 3-12, 2017.

26. Tsonis AI, Afratis N, Gialeli C, Ellina MI, Piperigkou Z, Skandalis SS, Theocharis AD, Tzanakakis GN and Karamanos NK: Evaluation of the coordinated actions of estrogen receptors with epidermal growth factor receptor and insulin-like growth factor receptor in the expression of cell surface heparan sulfate proteoglycans and cell motility in breast cancer cells. FEBS J 280: 2248-2259, 2013.

27. Hsieh DJ, Kuo WW, Lai YP, Shibu MA, Shen CY, Pai P, Yeh YL, Lin JY, Viswanadha VP and Huang CY: 17 $\beta$-estradiol and/or estrogen receptor $\beta$ attenuate the autophagic and apoptotic effects induced by prolonged hypoxia through HIF-1 $\alpha$-mediated BNIP3 and IGFBP-3 signaling blockage. Cell Physiol Biochem 36: 274-284, 2015.

28. Panic A, Stanimirovic J, Obradovic M, Zafirovic S Sudar-Milovanovic E, Petrovic N and Isenovic ER: 17 $\beta$-estradiol inhibits hepatic iNOS via the activation of the estrogen receptor $\mathrm{ER} \alpha$ and inhibition of erk1/2-mir-221 axis. J Biol Regul Homeost Agents 32: 1369-1377, 2018.

29. Go RE, Hwang KA, Kim CW, Byun YS, Nam KH and Choi KC: Effect of dioxin and $17 \beta$-estradiol on the expression of cytochrome P450 1A1 gene via an estrogen receptor dependent pathway in cellular and xenografted models. Environ Toxicol 32: 2225-2233, 2017.

30. Lee SH and Nam HS: TNF alpha-induced down-regulation of estrogen receptor alpha in MCF-7 breast cancer cells. Mol Cells 26: 285-290, 2008.

31. Boerner JL, Gibson MA, Fox EM, Posner ED, Parsons SJ, Silva CM and Shupnik MA: Estrogen negatively regulates epidermal growth factor (EGF)-mediated signal transducer and activator of transcription 5 signaling in human EGF family receptor-overexpressing breast cancer cells. Mol Endocrinol 19: 2660-2670, 2005.

32. Huang J,Li X, Yi P, Hilf R, Bambara RA and Muyan M: Targeting estrogen responsive elements (EREs): Design of potent transactivators for ERE-containing genes. Mol Cell Endocrinol 218: 65-78, 2004.

33. Bartucci M, Morelli C, Mauro L, Ando S and Surmacz E: Differential insulin-like growth factor I receptor signaling and function in estrogen receptor (ER)-positive MCF-7 and ER-negative MDA-MB-231 breast cancer cells. Cancer Res 61: 6747-6754, 2001.

34. Zhou Y, Eppenberger-Castori S, Marx C, Yau C, Scott GK, Eppenberger U and Benz CC: Activation of nuclear factor-kappaB (NFkappaB) identifies a high-risk subset of hormone-dependent breast cancers. Int J Biochem Cell Biol 37: 1130-1144, 2005.

35. Singh RR and Kumar R: Steroid hormone receptor signaling in tumorigenesis. J Cell Biochem 96: 490-505, 2005.

36. Song RX, McPherson RA, Adam L, Bao Y, Shupnik M, Kumar R and Santen RJ: Linkage of rapid estrogen action to MAPK activation by ERalpha-Shc association and Shc pathway activation. Mol Endocrinol 16: 116-127, 2002.

37. Zhou Y, Yau C, Gray JW, Chew K, Dairkee SH, Moore DH, Eppenberger U, Eppenberger-Castori S and Benz CC: Enhanced NF kappa B and AP-1 transcriptional activity associated with antiestrogen resistant breast cancer. BMC Cancer 7: 59, 2007.

38. Filardo EJ, Quinn JA, Frackelton AR Jr and Bland KI: Estrogen action via the G protein-coupled receptor, GPR30: Stimulation of adenylyl cyclase and cAMP-mediated attenuation of the epidermal growth factor receptor-to-MAPK signaling axis. Mol Endocrinol 16: 70-84, 2002. 